\title{
Septoplasty versus non-surgical management for nasal obstruction in adults with a deviated septum: economic evaluation alongside a randomized controlled trial
}

\author{
M. M. H. T. van Egmond ${ }^{1 *}$, J. P. C. Grutters ${ }^{2,3}$, G. Hannink ${ }^{2}$, N. van Heerbeek ${ }^{1}$ and M. M. Rovers ${ }^{2,3}$
}

\begin{abstract}
Background: For years, the benefits of septoplasty have been questioned. Due to the scarce and inconclusive literature, several National Health Service (NHS) Clinical Commissioning Groups in England decided to add septal surgery to their list of restricted procedures with low clinical value. Recently, evidence was obtained that septoplasty is actually more effective than non-surgical management for nasal obstruction in adults with a deviated septum. However, the relation between costs and effects of septoplasty remains unknown.

Methods: We conducted an economic evaluation alongside an open, multicenter, pragmatic randomized controlled trial in two tertiary and 16 secondary referral hospitals in the Netherlands. Adults with nasal obstruction and a deviated septum were randomized to (1) septoplasty with or without concurrent turbinate surgery or (2) non-surgical management consisting of (a combination of) medical treatment and watchful waiting. Analyses were performed on an intention-to-treat basis. Single imputation nested in the bootstrap percentile method (using 5000 bootstrap replications) was performed to assess the effect of missing data. After 12 and 24 months, we assessed the incremental costs per quality-adjusted life year (QALY) gained from a healthcare and a societal perspective.
\end{abstract}

(Continued on next page)

\footnotetext{
* Correspondence: Machteld.vanEgmond@radboudumc.nl

'Department of Otorhinolaryngology, Radboud Institute for Health Sciences,

Radboud University Medical Center, Route 377, P.O. Box 9101, 6500 HB

Nijmegen, the Netherlands

Full list of author information is available at the end of the article
}

(c) The Author(s). 2020 Open Access This article is licensed under a Creative Commons Attribution 4.0 International License, which permits use, sharing, adaptation, distribution and reproduction in any medium or format, as long as you give appropriate credit to the original author(s) and the source, provide a link to the Creative Commons licence, and indicate if changes were made. The images or other third party material in this article are included in the article's Creative Commons licence, unless indicated otherwise in a credit line to the material. If material is not included in the article's Creative Commons licence and your intended use is not permitted by statutory regulation or exceeds the permitted use, you will need to obtain permission directly from the copyright holder. To view a copy of this licence, visit http://creativecommons.org/licenses/by/4.0/ The Creative Commons Public Domain Dedication waiver (http://creativecommons.org/publicdomain/zero/1.0/) applies to the data made available in this article, unless otherwise stated in a credit line to the data. 
(Continued from previous page)

Results: A total of 203 adults were randomly assigned to septoplasty ( $N=102)$ or non-surgical management $(N=$ 101). After 12 months, the mean cost difference between septoplasty and non-surgical management using a healthcare or societal perspective was $€ 1181$ (95\% Cl $€ 1038$ to $€ 1323)$ or $€ 2192$ per patient (95\%Cl $€ 1714$ to $€ 2670)$, respectively. The mean QALY difference was 0.03 per patient $(95 \% \mathrm{Cl}-0.01$ to 0.07$)$. Incremental costs per QALY gained from a healthcare or societal perspective were $€ 41,763$ or $€ 77,525$, respectively. After 24 months, the mean cost difference between the two groups using a healthcare or societal perspective decreased to $€ 936$ (95\%Cl €719 to $€ 1153$ ) or $€ 1671$ per patient (95\% Cl $€ 952$ to $€ 2390)$, respectively. The mean QALY difference increased to 0.05 per patient $(95 \% \mathrm{Cl}-0.03$ to 0.14$)$. Incremental costs per QALY gained from a healthcare or societal perspective became $€ 17,374$ or $€ 31,024$, respectively. Analyses of imputed data did not alter our findings.

Conclusions: Depending on the selected perspective, cost-effectiveness threshold, and time horizon, septoplasty has the potential to be cost-effective. Despite considerable uncertainty, septoplasty seems to be cost-effective from a healthcare perspective, after 24 months against a threshold of $€ 20,000$ per QALY. From a societal perspective, septoplasty is not yet cost-effective after 24 months, but it comes closer to the cost-effectiveness threshold as time passes by.

Trial registration: Nederlands Trial Register, NTR3868 (https://www.trialregister.nl/trial/3698). Prospectively registered on February 21, 2013.

Keywords: Septoplasty, Nasal obstruction, Nasal septal deviation, Quality-adjusted life year (QALY), Costeffectiveness, Randomized controlled trial (RCT), Economic evaluation, Health policy

\section{Background}

Septoplasty (surgical correction of the deviated septum) is the most frequently performed ear, nose, and throat operation in adults, but its effectiveness has long been questioned [1]. The British National Institute for Health Research (NIHR) and professional associations of ear, nose, and throat surgeons in the UK and the Netherlands highly prioritized studies on this topic, considering it as one of the most important evidence gaps in otorhinolaryngology [2-4]. However, despite the call for further research, the literature has remained scarce and inconclusive for years [5]. As a result, several National Health Service (NHS) Clinical Commissioning Groups in England have added septal surgery to their list of restricted procedures, characterizing septoplasty as an intervention of low clinical value $[6,7]$. In early 2019, the German Ear, Nose, and Throat Society released a position paper which referred to the controversy and discussed possible criteria for performing septoplasty, most notably the presence of chronic functional impairment of nasal breathing (with or without concomitant disease of the upper or lower respiratory tract) [8].

Recently, the first randomized controlled trial on the effectiveness of septoplasty showed that septal surgery is in fact superior to non-surgical management for nasal obstruction in adults with a deviated septum [9]. Both health-related quality of life and objective measurements of nasal airflow were found to improve after septoplasty. Nonetheless, previous modeling research demonstrated that septal surgery incurs significant additional costs compared to non-surgical management [10]. Considering the rising demand for care and growing strain on resources, it is important to weigh the benefits of an intervention against its costs, in order to justify its use to society [11].

Alongside the randomized controlled trial on the effectiveness of septoplasty, we collected data on healthcare and societal costs incurred by septal surgery and non-surgical management over the full 24 months of follow-up. The aim of the current study is to determine whether septoplasty is a cost-effective strategy for nasal obstruction in adults with a deviated septum, as the first step towards evidence-based policy-making in this field.

\section{Methods}

\section{Design, setting, and participants}

An economic evaluation was conducted alongside an open, multicenter, pragmatic randomized controlled trial in two tertiary and 16 secondary referral hospitals in the Netherlands. The study was performed in accordance with the CONSORT 2010 and CHEERS 2013 guidelines $[12,13]$. The protocol was approved by the accredited medical ethics committee of the Radboud University Medical Center, Nijmegen. The study design has been reported previously [14]. In short, adults with nasal obstruction, a deviated septum, and an indication to have septoplasty performed (with or without concurrent turbinate surgery) were included in the trial between September 2013 and December 2016. We excluded patients with a history of septal surgery, patients with septal perforation, patients with untreated allergic rhinitis or allergic rhinitis unresponsive to medical treatment, patients in whom nasal obstruction was not the primary indication for septoplasty, 
patients in whom septoplasty was to be performed as part of a cosmetic rhinoplasty procedure, and cleft lip and/or palate patients.

After eligible patients had provided written informed consent, their demographic and disease-specific data were collected, subjective and objective outcomes were administered, and they were randomly assigned to a treatment arm.

\section{Randomization}

An independent data manager developed a computerized minimization strategy, taking into account sex, age $(<35$ years or $\geq 35$ years), and severity of the deviation (mild, moderate, or severe) $[15,16]$. Treatment allocation was concealed and balanced in a 1:1 ratio for the two comparators: septoplasty and non-surgical management.

\section{Comparators}

Patients assigned to septoplasty underwent septal surgery with or without concurrent turbinate surgery as considered appropriate by their ear, nose, and throat surgeon, following regular clinical practice. The septal deviation needed to be the primary contributing factor to impaired nasal breathing. However, since turbinate enlargement often accompanies a deviated septum, additional minor turbinate surgery was allowed to prevent residual postoperative complaints of nasal obstruction [17]. The operation was scheduled within 6 to 8 weeks after the baseline visit. Patients assigned to non-surgical management underwent (a combination of) conservative strategies, which is watchful waiting and medical treatment, the latter usually consisting of local corticosteroids. Both surgical and non-surgical patients were allowed to use additional medication if needed, in line with the pragmatic nature of the trial.

\section{Time horizon}

Follow-up visits were scheduled at 3, 6, 12, and 24 months. If patients assigned to non-surgical management underwent septoplasty within the 24 months of trial follow-up, they were classified as cross-over and monitored as planned (intention-to-treat protocol). During each follow-up visit, subjective and objective outcomes were measured and a patient-reported cost diary was collected.

\section{Study perspectives}

An economic evaluation can be conducted from a healthcare perspective or a broader societal perspective. The healthcare perspective includes direct medical costs due to treatment and follow-up, such as medication use and healthcare contacts. The societal perspective additionally includes broader costs to society, such as direct non-medical costs (travel expenses) and indirect costs (productivity losses) [18]. The British National Institute for Health and Care Excellence (NICE) primarily focuses on costs reimbursed by the NHS and Personal Social Services (PSS) [19]. Therefore, NICE advises the use of the healthcare perspective [20]. In contrast, the Dutch guideline for economic evaluation recommends the societal perspective, taking all relevant costs into account irrespective of the payer [21]. Our analysis was performed from both a healthcare and a societal perspective.

\section{Measures of effectiveness}

The economic evaluation was conducted using three measures of effectiveness: quality-adjusted life years (QALYs), disease-specific quality of life, and nasal airflow.

QALYs are a combination of years of life and generic health-related quality of life. Generic health-related quality of life was assessed at baseline, 3, 6, 12, and 24 months using the EuroQol five dimensions three levels (EQ-5D3L) [22]. The EQ-5D-3L provides a measure of health state, which can be converted into a single utility score ranging from 0 (death) to 1 (full health). Utility scores were calculated using the Dutch value set [23]. Based on these utility scores, QALYs were computed using the area under the curve approach. After the first year of followup, QALYs were discounted at a rate of 1.5\% [21].

Disease-specific quality of life was measured using the Nasal obstruction symptom evaluation (NOSE) $[24,25]$. Total NOSE scores range from 0 to 100, with lower scores indicating better outcomes. To facilitate interpretation, the direction of the NOSE was inverted so that higher scores represented better results. Based on the validated minimal important change of 5.3 points on the NOSE [26], we calculated the proportion of responders (who gained 6 points or more) and non-responders (who either lost points or gained 5 points or less) for each of the two treatment strategies.

Nasal airflow in liter per minute $(\mathrm{L} / \mathrm{min})$ through both nostrils (before mucosal decongestion) was objectively assessed by means of peak nasal inspiratory flow (PNIF) [27]. The instrument used for PNIF was produced by Clement Clarke International Ltd. (Essex, UK). The average gain from baseline in nasal airflow (in percentages) was calculated for each of the two groups.

\section{Costs}

Resource use was prospectively measured using a patient-reported cost diary, which covered the full 24 months of follow-up and was periodically collected during each study visit. The diary measured the number of resources used due to nasal complaints, such as days of medication use, healthcare contacts, kilometers traveled, hours of work lost, and hours of household work lost. Residual expenses and parking costs were obtained directly from the patient-reported cost diary. Other costs 
were calculated by multiplying the number of resources used with the corresponding cost price. Cost prices for healthcare contacts, kilometers traveled, hours of work lost, and hours of household work lost were based on the Dutch guideline for economic evaluation [21]. Cost prices for the medication (both prescribed and over-the-counter) were derived from the Dutch formulary [28]. The cost price of septal surgery was based on the Dutch guideline for economic evaluation and data from the Radboud University Medical Center, Nijmegen [21]. Follow-up visits for the study were excluded from the analysis. All costs were based on the 2017 price level. The average exchange rate of euro versus pound sterling and euro versus US dollar in 2017 was $€ 1.00=£ 0.88$ and $€ 1.00=\$ 1.13$, respectively [29]. Costs occurring after the first year of follow-up were discounted at a rate of $4 \%$ [21].

\section{Statistical analysis}

Mean differences between septoplasty and non-surgical management in costs and QALYs per patient were calculated. If septoplasty was more costly and more effective, or less costly and less effective, we computed the incremental cost-effectiveness ratio (ICER), at 12 and 24 months. This ICER represents the additional costs per QALY gained, or the costs saved per QALY lost. Following the Dutch guideline for economic evaluation, we used a cost-effectiveness threshold of $€ 20,000$ per QALY [21]. Moreover, we calculated the incremental costs per extra responder on the NOSE (gaining the validated minimal important change of 5.3 points or more) and per percentage point gain in nasal airflow as measured with PNIF, at 12 and 24 months [26]. As cost data are generally highly skewed and not normally distributed, we used BCA bootstrapping with 5000 replications to estimate 95\% confidence intervals around the costs and effects [30]. Non-parametric bootstrapping with 5000 replications was used to create costeffectiveness planes and cost-effectiveness acceptability curves. Cost-effectiveness acceptability curves were derived at 12 and 24 months, illustrating the probability of cost-effectiveness against different cost-effectiveness thresholds [31]. All analyses were performed on an intention-to-treat basis. As recommended in a recent study by Brand et al., the effect of missing data was assessed with single imputation nested in the bootstrap percentile method [32]. First, bootstrapping was used to generate 5000 incomplete datasets, and second, a single completed dataset was generated for every incomplete dataset (see Additional file 1 for a detailed description). Analyses were performed with SPSS version 22.0 (SPSS, Armonk, NY, USA), Microsoft Excel 2016 (Microsoft Corporation, Redmond, WA, USA), and $\mathrm{R}$ version 3.6.2 ( $\mathrm{R}$ Project for Statistical Computing, Vienna, Austria).

\section{Results}

\section{Participant characteristics}

A total of 260 potential participants were registered with our research team. As 57 patients either did not fulfill eligibility criteria or were not willing to participate, we included the remaining 203 eligible patients into the study. All included patients were randomized: 102 were assigned to septoplasty and 101 to non-surgical management. Clinical characteristics at baseline did not differ between the two groups (Table 1). The total population consisted of more males than females $(N=138,68 \%)$, the mean age was 38 years (SD 15), and the median duration of nasal obstruction before trial entry was 7 years (IQR 12). Analyses at 12 months were conducted in 90 patients $(88 \%)$ assigned to septoplasty and 92 patients (91\%) assigned to non-surgical management, and at 24 months, in 68 patients $(67 \%)$ assigned to septoplasty and 65 patients (64\%) assigned to non-surgical management (Fig. 1).

\section{Costs}

An overview of the resources used and the corresponding cost prices is provided in Table 2. The mean component and total costs per patient from a healthcare or societal perspective after 12 and 24 months for each of the two treatment strategies are shown in Table 3.

\section{Healthcare perspective}

After 12 months, the mean healthcare costs per patient assigned to septoplasty and non-surgical management were $€ 1670$ (95\% CI $€ 1634$ to $€ 1710$ ) and $€ 489$ (95\% CI $€ 359$ to $€ 622$ ), respectively. The mean cost difference between the two groups was $€ 1181$ (95\% CI €1038 to €1323).

After 24 months, the mean healthcare costs per surgical and non-surgical patient were $€ 1663$ (95\% CI $€ 1623$ to $€ 1706$ ) and $€ 727$ (95\% CI $€ 533$ to $€ 941$ ), respectively. The mean cost difference between the two groups decreased to $€ 936$ (95\% CI $€ 719$ to $€ 1153$ ).

\section{Societal perspective}

After 12 months, the mean societal costs per patient assigned to septoplasty and non-surgical management were $€ 3404$ (95\% CI $€ 3108$ to $€ 3702$ ) and $€ 1212$ (95\% CI $€ 881$ to $€ 1575)$, respectively. The mean cost difference between the two groups was $€ 2192$ (95\%CI $€ 1714$ to $€ 2670$ ).

After 24 months, the mean societal costs per surgical and non-surgical patient became $€ 3423$ (95\%CI $€ 3088$ to $€ 3767)$ and $€ 1752$ (95\%CI €1234 to €2393), respectively. The mean cost difference between the two groups decreased to $€ 1671$ (95\%CI $€ 952$ to $€ 2390$ ). 
Table 1 Baseline characteristics of the trial population

\begin{tabular}{lll}
\hline Characteristic & $\begin{array}{l}\text { Septoplasty (with or } \\
\text { without concurrent } \\
\text { turbinate surgery), } \\
N=102\end{array}$ & management, \\
& $N=101$ \\
\hline
\end{tabular}

Age, years

$\begin{array}{cll}\text { Mean } \pm \text { SD } & 39 \pm 14 & 37 \pm 15 \\ \text { Range } & 18 \text { to } 67 & 18 \text { to } 70 \\ \text { Male sex, no. (\%) } & 73(72) & 66(65)\end{array}$

Body mass index

$\begin{array}{lll}\text { Mean } \pm \text { SD } & 25.0 \pm 4.5 & 25.6 \pm 3.8 \\ \text { Range } & 16.7 \text { to } 39.9 & 17.5 \text { to } 38.7\end{array}$

Duration of nasal obstruction, years

\begin{tabular}{|c|c|c|}
\hline Median & 6 & 8 \\
\hline IQR & 10 & 11 \\
\hline Nasal obstruction bilateral, no. (\%) & $64(63)$ & $61(60)$ \\
\hline $\begin{array}{l}\text { Previous treatment for nasal } \\
\text { obstruction, no. (\%) }\end{array}$ & $81(79)$ & $87(86)$ \\
\hline Local corticosteroids, no. (\%) & $73(72)$ & $73(72)$ \\
\hline Nasal decongestants, no. (\%) & $39(38)$ & $42(42)$ \\
\hline Turbinate surgery, no. (\%) & $2(2)$ & $3(3)$ \\
\hline History of nasal trauma, no. (\%) & $42(41)$ & $42(42)$ \\
\hline \multicolumn{3}{|l|}{ Smoking status } \\
\hline Current smoker, no. (\%) & $26(25)$ & $34(34)$ \\
\hline History of smoking, no. (\%) & $34(33)$ & $30(30)$ \\
\hline Cocaine abuse, no. (\%) & $7(7)$ & $11(11)$ \\
\hline Snoring ${ }^{\dagger}$, no. (\%) & $50(49)$ & $44(44)$ \\
\hline Allergic rhinitis ${ }^{\dagger}$, no. (\%) & $32(31)$ & $30(30)$ \\
\hline Asthma $^{\dagger}$, no. (\%) & $24(24)$ & $18(18)$ \\
\hline Turbinate hypertrophy, no. (\%) & $46(45)$ & $47(47)$ \\
\hline Unilateral, no. (\%) & $29(28)$ & $24(24)$ \\
\hline Bilateral, no. (\%) & $16(16)$ & $18(18)$ \\
\hline Septal deviation bilateral, no. (\%) & $25(25)$ & $23(23)$ \\
\hline \multicolumn{3}{|l|}{ Septal deviation severity ${ }^{\ddagger}$} \\
\hline Mild, no. (\%) & $32(31)$ & $27(27)$ \\
\hline Moderate, no. (\%) & $66(65)$ & $67(66)$ \\
\hline Severe, no. (\%) & $37(36)$ & $32(32)$ \\
\hline \multicolumn{3}{|l|}{ Measures of effectiveness } \\
\hline $\begin{array}{l}\text { EQ-5D-3L utility score, } \\
\text { mean } \pm S D\end{array}$ & $0.83 \pm 0.19$ & $0.82 \pm 0.19$ \\
\hline EQ-5D-3L VAS, mean $\pm S D$ & $72.1 \pm 16.1$ & $74.1 \pm 17.0$ \\
\hline NOSE, mean \pm SD & $32.8 \pm 18.1$ & $34.4 \pm 19.3$ \\
\hline $\mathrm{PNIF}$, mean $\pm \mathrm{SD}^{\S}$ & $91.6 \pm 39.0$ & $87.1 \pm 40.5$ \\
\hline
\end{tabular}

${ }^{\dagger}$ Self-reported; no diagnostics performed as part of the trial

FThe deviation was classified by the ear, nose, and throat surgeon as mild if it obstructed less than half of the nasal passage, as moderate if it obstructed half or more than half of the nasal passage, and as severe if the deviation was in contact with the lateral nasal wall

${ }^{5}$ Presented values are before the decongestion of the nasal mucosa

\section{Economic evaluation}

\section{Costs per QALY}

After 12 months, patients assigned to septoplasty and non-surgical management had on average 0.88 QALYs (95\%CI 0.85 to 0.91 ) and 0.85 QALYs (95\%CI 0.83 to $0.88)$, respectively. The mean QALY difference between the two groups was $0.03(95 \% \mathrm{CI}-0.01$ to 0.07$)$. Incremental costs per QALY gained from septoplasty were $€ 41,763$ from a healthcare perspective and $€ 77,525$ from a societal perspective.

After 24 months, surgical and non-surgical patients had on average 1.78 QALYs (95\%CI 1.71 to 1.84 ) and 1.73 QALYs (95\%CI 1.67 to 1.78$)$, respectively. The mean QALY difference between the two treatment strategies increased to 0.05 ( $95 \% \mathrm{CI}-0.03$ to 0.14$)$. Incremental costs per QALY gained from septoplasty became $€ 17$, 343 from a healthcare perspective and $€ 31,024$ from a societal perspective.

\section{NOSE}

After 12 months, 74 out of 90 surgical patients (82\%) and 49 out of 92 non-surgical patients (53\%) could be classified as responders on the NOSE, gaining the validated minimal important change of 5.3 points or more [26]. The mean difference between the two groups in percentage point response was 29 (95\%CI 16 to 42 ). Based on a mean difference in societal costs between the two groups of $€ 2192$ (95\%CI $€ 1714$ to $€ 2670$ ), incremental costs per extra responder on the NOSE were $€ 7568$.

After 24 months, 53 out of 68 surgical patients (78\%) and 30 out of 65 non-surgical patients (46\%) were responders, gaining the validated minimal important change of 5.3 points or more [26]. The mean difference between the two groups in percentage point response was 32 (95\% CI 16 to 48). Given a mean difference in societal costs between the two groups of $€ 1671$ (95\%CI $€ 952$ to €2390), incremental costs per extra responder on the NOSE were $€ 5256$.

\section{PNIF}

After 12 months, the mean gain from baseline in nasal airflow as measured with PNIF in surgical and nonsurgical patients was $45 \%$ (95\% CI 34 to $56 \%$ ) and $24 \%$ (95\% CI 11 to $37 \%$ ), respectively. The mean difference between the two groups in percentage point gain in nasal airflow was 21 (95\% CI 4 to 38). Based on a mean difference in societal costs between the two groups of $€ 2384$ (95\% CI $€ 1873$ to $€ 2895$ ), incremental costs per percentage point gain in nasal airflow were $€ 113$.

After 24 months, the mean gain from baseline in nasal airflow as measured with PNIF in surgical and nonsurgical patients was $40 \%$ (95\% CI 27 to 55\%) and $28 \%$ (95\% CI 13 to 43\%), respectively. The mean difference between the two groups in percentage point gain in 


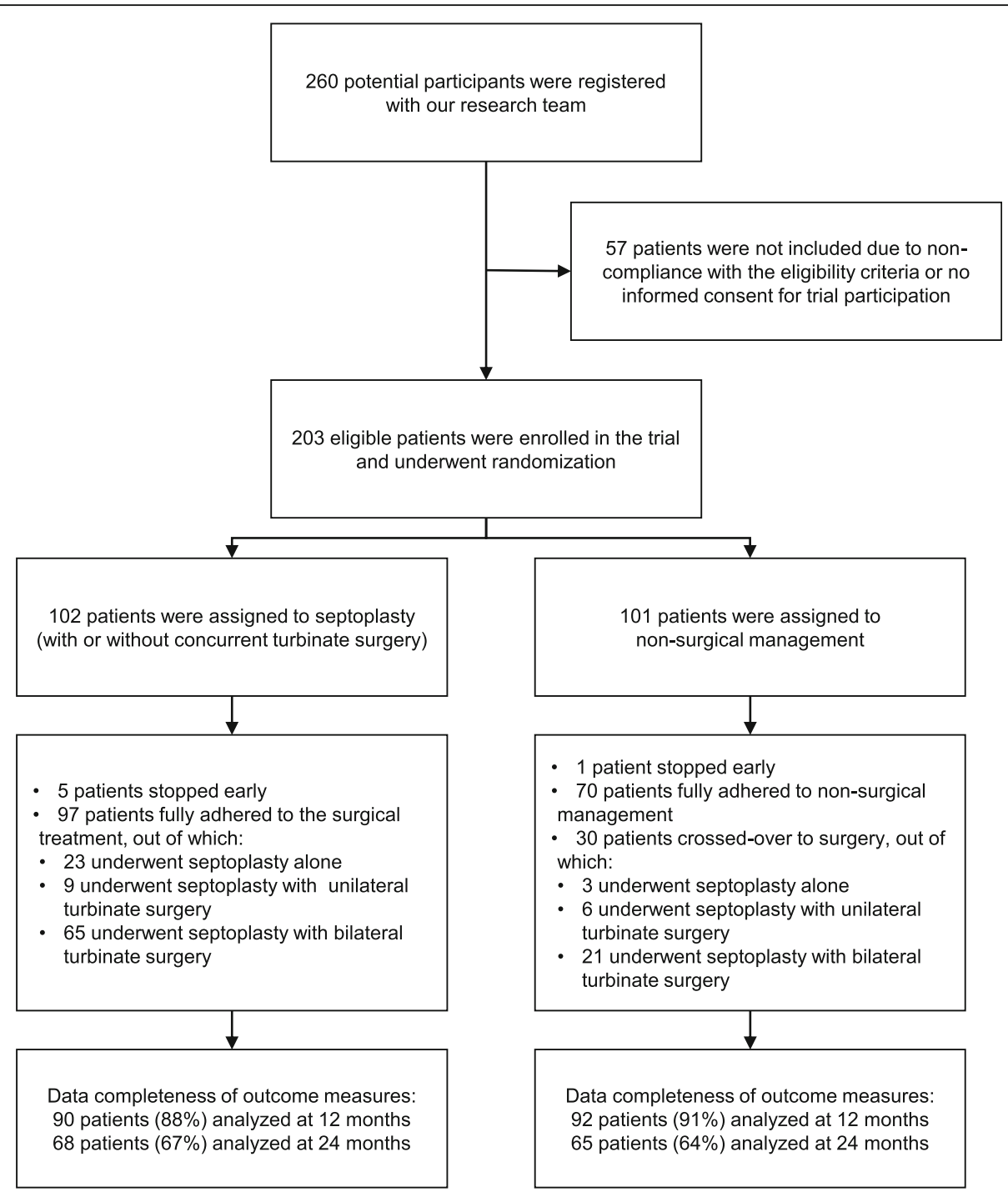

Fig. 1 Randomization, adherence to assigned treatment, and data completeness (based on the CONSORT flow diagram)

nasal airflow was 13 (95\%CI -9 to 35). Given a mean difference in societal costs between the two groups of $€ 1790$ (95\%CI $€ 777$ to $€ 2803$ ), incremental costs per percentage point gain in nasal airflow were $€ 139$.

\section{Uncertainty}

Cost-effectiveness planes, providing a graphical overview of incremental costs and QALYs after 12 and 24 months for each of the bootstrap replications, are shown in Fig. $2 \mathrm{a}$ and $\mathrm{b}$ for the healthcare perspective and Fig. 2c and $\mathrm{d}$ for the societal perspective.

Acceptability curves, illustrating the probability that septoplasty is cost-effective after 12 and 24 months against different cost-effectiveness thresholds, are provided in Fig. 3a for the healthcare perspective and Fig. 3b for the societal perspective. From a healthcare perspective, septoplasty was cost-effective in $7 \%$ of the replications after 12 months and in $56 \%$ of the replications after 24 months, and from a societal perspective, septoplasty was costeffective in $0 \%$ of the replications after 12 months and in $25 \%$ of the replications after 24 months, all against a costeffectiveness threshold of $€ 20,000$ per QALY. In line with the base-case estimates, the majority of bootstrap replications thus indicate that septoplasty is cost-effective from a healthcare perspective after 24 months. Furthermore, while septoplasty is not yet cost-effective from a societal perspective after 24 months, it progresses towards the cost-effectiveness threshold as time passes by.

\section{Imputation of missing data}

Table S1, Figures S1a-S1d, and Figures S2a-S2b in Additional file 1 provide an overview of the complete case analyses and single imputation nested in the bootstrap percentile method (using 5000 bootstrap replications). 
Table 2 Resources used with their corresponding cost price for 2017. The average exchange rate of euro versus pound sterling and euro versus US dollar in 2017 was $€ 1.00=£ 0.88$ and $€ 1.00=\$ 1.13$, respectively [29]

\begin{tabular}{|c|c|c|}
\hline Resource & Cost price in $€$ & Source \\
\hline \multicolumn{3}{|l|}{ Medication use (per day) } \\
\hline Local corticosteroids & 0.38 & Formulary \\
\hline Oral corticosteroids & 0.14 & Formulary \\
\hline Decongestants & 0.33 & Formulary \\
\hline Analgesics & 0.85 & Formulary \\
\hline Antibiotics & 1.87 & Formulary \\
\hline Antihistamines & 0.23 & Formulary \\
\hline Saline solution & 0.07 & Formulary \\
\hline Nasal ointment & 0.67 & Formulary \\
\hline \multicolumn{3}{|l|}{ Healthcare contacts } \\
\hline General practitioner visit during office hours & 34.00 & Guideline \\
\hline General practitioner visit after office hours & 109.11 & Guideline \\
\hline $\begin{array}{l}\text { General practitioner telephone } \\
\text { consultation during office hours }\end{array}$ & 17.00 & Guideline \\
\hline $\begin{array}{l}\text { General practitioner telephone } \\
\text { consultation after office hours }\end{array}$ & 25.00 & Guideline \\
\hline Medical specialist visit during office hours & 93.00 & Guideline \\
\hline Medical specialist visit after office hours & 265.00 & Guideline \\
\hline $\begin{array}{l}\text { Medical specialist telephone } \\
\text { consultation during office hours }\end{array}$ & 19.79 & Guideline \\
\hline $\begin{array}{l}\text { Medical specialist telephone } \\
\text { consultation after office hours }\end{array}$ & 29.03 & Guideline \\
\hline $\begin{array}{l}\text { Medical assistant/therapist visit } \\
\text { during office hours }\end{array}$ & 33.00 & Guideline \\
\hline \multicolumn{3}{|l|}{ Surgery } \\
\hline $\begin{array}{l}\text { Septoplasty (with or without } \\
\text { concurrent turbinate surgery) }\end{array}$ & 1241 & $\begin{array}{l}\text { Guideline and } \\
\text { Radboudume }\end{array}$ \\
\hline \multicolumn{3}{|l|}{ Travel expenses } \\
\hline Taxi kilometer fare & 2.72 & Guideline \\
\hline Taxi start rate & 3.02 & Guideline \\
\hline Car/motor/public transport kilometer fare & 0.19 & Guideline \\
\hline Parking & NA & Cost diary \\
\hline \multicolumn{3}{|l|}{ Productivity losses } \\
\hline $\begin{array}{l}\text { Hour of work lost (due to } \\
\text { healthcare visits) }\end{array}$ & 34.36 & Guideline \\
\hline $\begin{array}{l}\text { Hour of household work lost } \\
\text { (due to healthcare visits) }\end{array}$ & 14.32 & Guideline \\
\hline $\begin{array}{l}\text { Hour of work or household work lost } \\
\text { (due to illness or postoperative recovery) }\end{array}$ & 32.64 & Guideline \\
\hline \multicolumn{3}{|l|}{ Residual expenses } \\
\hline Paid help & NA & Cost diary \\
\hline Others & NA & Cost diary \\
\hline
\end{tabular}

Cost diary patient-reported cost diary, Formulary Dutch formulary [28], Guideline Dutch guideline for economic evaluation [21], NA not applicable, Radboudumc Radboud University Medical Center, Nijmegen

Generally, the results of both methods were comparable. The difference between septoplasty and non-surgical management in healthcare costs at 12 and 24 months and societal costs at 12 months was slightly smaller with single imputation nested in the bootstrap percentile method than with complete case analyses, thereby increasing the cost-effectiveness of septal surgery. The only exception was societal costs at 24 months. However, this did not affect the conclusion, as the complete case analyses too demonstrated that septoplasty was not yet cost-effective from a societal perspective after two years.

\section{Discussion}

\section{Principal findings}

This economic evaluation, performed alongside a randomized controlled trial, showed that septoplasty is both more effective and more costly than non-surgical management for nasal obstruction in adults with a deviated septum. However, surgical costs are predominantly incurred in the first year, whereas costs of non-surgical management gradually accumulate as the treatment continues. Accordingly, the cost difference between surgical and non-surgical treatment was found to decrease over time, while the difference in health-related quality of life between the two groups persisted. Incremental costs per QALY gained after 12 months were $€ 41,763$ from a healthcare perspective and $€ 77,525$ from a societal perspective. After 24 months, incremental costs per QALY gained became $€ 17,374$ from a healthcare perspective and $€ 31,024$ from a societal perspective. Given a costeffectiveness threshold of $€ 20,000$ per QALY, septoplasty is cost-effective from a healthcare perspective. While septoplasty is not yet cost-effective from a societal perspective after 2 years, it comes closer to the costeffectiveness threshold as time passes by.

\section{Comparison with the literature}

Randomized controlled trials or non-randomized comparative studies on the (cost-) effectiveness of septoplasty have not been published before [5]. Previous modeling research based on publicly available data sources demonstrated that septoplasty incurs significant additional costs compared to non-surgical management, especially considering the productivity losses due to postoperative recovery [10]. However, as effectiveness data were lacking, the relation between costs and effects of septal surgery remained unclear.

\section{Strengths and weaknesses}

The main strength of our study is that this is the first trial-based economic evaluation of septoplasty. Data on costs and effects were prospectively and simultaneously collected in an open, multicenter, pragmatic randomized controlled trial. The economic evaluation was conducted from a healthcare and societal perspective and was performed and reported in accordance with the CONSORT 2010 and CHEERS 2013 guidelines [12, 13]. 
Table 3 Mean component costs and mean total healthcare and societal costs per patient for septoplasty and non-surgical management after 12 and 24 months. The average exchange rate of euro versus pound sterling and euro versus US dollar in 2017 was $€ 1.00=£ 0.88$ and $€ 1.00=\$ 1.13$, respectively [29]

\begin{tabular}{|c|c|c|c|c|}
\hline \multirow[t]{2}{*}{ Resource } & \multicolumn{4}{|c|}{ Mean costs in $€(95 \% \mathrm{Cl})$} \\
\hline & $\begin{array}{l}\text { Septoplasty, } 0-12 \\
\text { months }(N=90)\end{array}$ & $\begin{array}{l}\text { Non-surgical management, } \\
0-12 \text { months }(N=92)\end{array}$ & $\begin{array}{l}\text { Septoplasty, } 0-24 \\
\text { months }(N=68)\end{array}$ & $\begin{array}{l}\text { Non-surgical management, } \\
0-24 \text { months }(N=65)\end{array}$ \\
\hline Medication use & 41 (31 to 53 ) & 103 (87 to 119$)$ & 56 (38 to 78$)$ & 150 (123 to 179$)$ \\
\hline Healthcare contacts & 387 (355 to 423$)$ & 117 (82 to 155$)$ & 366 (334 to 400$)$ & 219 (143 to 313$)$ \\
\hline Surgery & 1241 (1241 to 1241$)$ & 270 (172 to 379$)$ & 1241 (1241 to 1241$)$ & 358 (227 to 492 ) \\
\hline Total healthcare costs & 1670 (1634 to 1710$)$ & 489 (359 to 622) & 1663 (1623 to 1706$)$ & 727 (533 to 941) \\
\hline Travel expenses & 37 (31 to 44$)$ & $9(5$ to 13$)$ & 41 (34 to 50$)$ & 15 (7 to 24$)$ \\
\hline Productivity losses & 1680 (1429 to 1947$)$ & 714 (475 to 1002$)$ & 1707 (1399 to 2019) & 999 (648 to 1416$)$ \\
\hline Residual expenses & 18 (3 to 36$)$ & 1 (0 to 2$)$ & 12 (3 to 26$)$ & 11 (2 to 24$)$ \\
\hline Total societal costs & 3404 (3108 to 3702 ) & $1212(881$ to 1575$)$ & 3423 (3088 to 3767) & 1752 (1234 to 2393) \\
\hline
\end{tabular}

Some of our findings deserve further attention. First, the study's follow-up was limited to 24 months. Because surgery is relatively costly in the first year but saves expenses in later years, the probability of septoplasty being cost-effective increases as time passes. From a healthcare perspective, septal surgery is already cost-effective after 24 months. From a societal perspective, septoplasty needs longer to compensate for its extra costs but will most likely become cost-effective over the course of the third or fourth postoperative year. This scenario holds

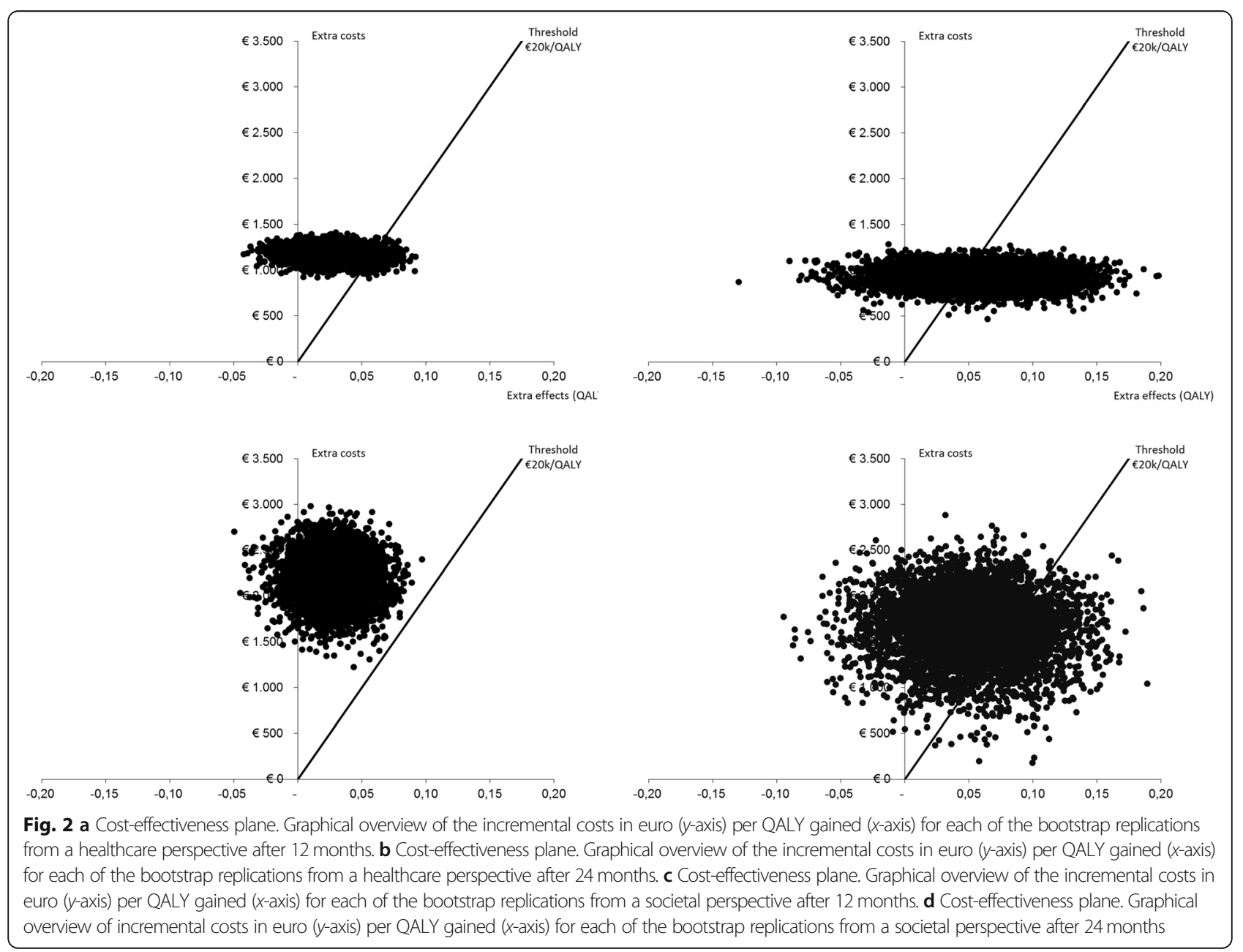



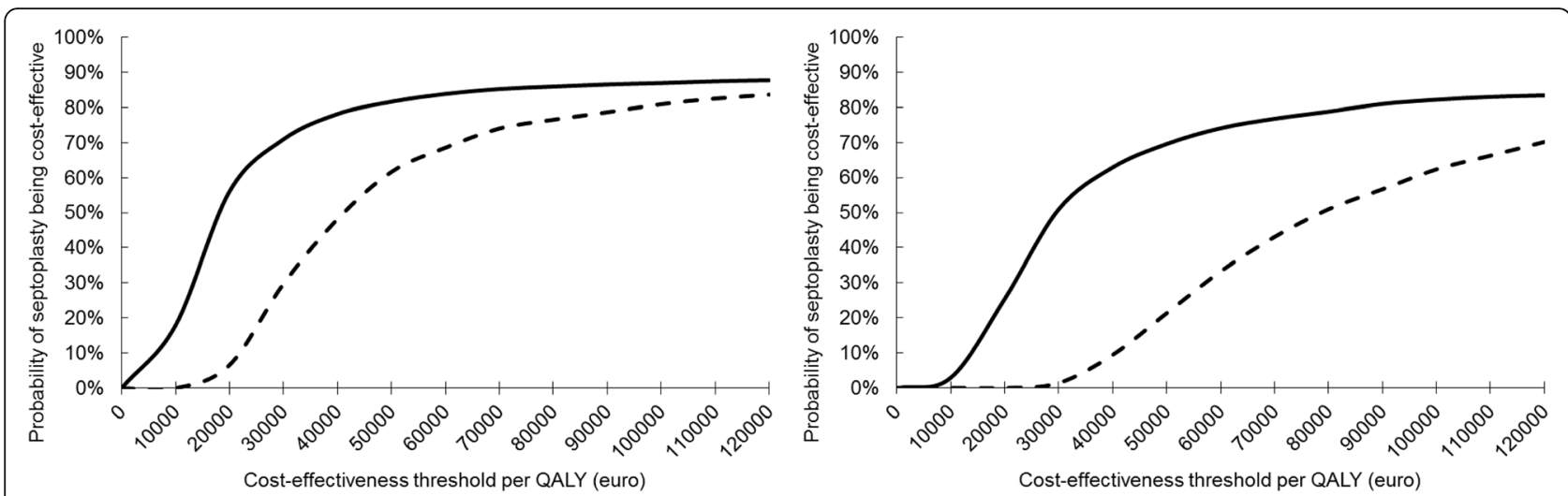

Fig. 3 a Acceptability curve illustrating the probability that septoplasty is cost-effective from a healthcare perspective ( $y$-axis) at different costeffectiveness thresholds ( $x$-axis) after 12 months (dashed line) and 24 months (solid line). Against a threshold of $€ 20,000$ per QALY, septoplasty was cost-effective in $7 \%$ of the replications after 12 months and in $56 \%$ of the replications after 24 months. b Acceptability curve illustrating the probability that septoplasty is cost-effective from a societal perspective ( $y$-axis) at different cost-effectiveness thresholds ( $x$-axis) after 12 months (dashed line) and 24 months (solid line). Against a threshold of $€ 20,000$ per QALY, septoplasty was cost-effective in $0 \%$ of the replications after 12 months and in $25 \%$ of the replications after 24 months

even if the QALY difference stabilizes after the second year, provided that the cost difference continues to decrease due to ongoing expenses for non-surgical treatment.

Second, generic health-related quality of life was measured with the EQ-5D-3L, but this instrument suffers from limited sensitivity and ceiling effects $[9,33]$. This may have resulted in an underestimation of the QALY difference between surgical and non-surgical patients. Even with the EQ-5D-3L, however, septoplasty was found to be (potentially) cost-effective.

Third, our randomized controlled trial included four other measures of effectiveness that were not taken into account in the economic evaluation [14]. This is because those instruments were less suited for the purpose of an economic evaluation: the EQ-5D-3L was the only instrument that could be used for QALY calculations; the NOSE was the only validated instrument for which a minimal important change was established; and PNIF was the objective instrument that appeared to assess nasal patency best $[9,22,26]$. All the measures of effectiveness included in our economic evaluation seem to indicate that septoplasty provides value for money.

Fourth, while surgical patients were regularly monitored by their operating ear, nose, and throat surgeon regardless of the study visits, non-surgical patients may have used the study visits as a replacement for regular outpatient consultation. This could be disadvantageous for the cost-effectiveness of septoplasty, as study visits were excluded from the analysis.

Fifth, most patients assigned to surgery underwent septoplasty with concurrent turbinate surgery, rather than septoplasty alone. Concurrent turbinate surgery was allowed, given the pragmatic nature of the trial. Stratified analysis performed as part of our effectiveness study did not point towards the potential modification of the effect of septoplasty [9]. From an economic perspective, the impact is limited as well: the costs of septoplasty alone and septoplasty with concurrent turbinate surgery are comparable, as the additional time investment is negligible and the materials required for turbinate surgery are routinely present during septoplasty. Given the limited number of patients who underwent septoplasty alone, however, we feel that our trial does not allow for firm conclusions about the (cost-)effectiveness of concurrent turbinate surgery.

Sixth, a total of $21(10 \%)$ patients at 12 months and 70 (35\%) patients at 24 months had (some) missing data. The majority of the missing values at 24 months were caused by the fixed stop date of the trial and were thus considered to be missing completely at random. In this case, complete case analysis provides valid and unbiased results reflecting the true estimates. Still, the effect of missing data was examined with single imputation nested in the bootstrap percentile method (using 5000 bootstrap replications), as recommended by Brand et al. [32]. These analyses of imputed data did not alter our findings.

Seventh, blinding of participants was impossible, as medical ethics committees in the Netherlands consider it unethical to perform sham surgery in the control group. However, we used both subjective and objective outcome measures, which showed similar results.

In short, the conclusion that septal surgery has the potential to compensate its extra costs appears to be robust. Some of the issues discussed above may have been unfavorable to septoplasty, but it was still cost-effective from a healthcare perspective after 24 months. 


\section{Clinical implications}

The effectiveness of septoplasty has long been questioned. Over the past decades, doubts surrounding its benefits have led to an increasing strain on septal surgery, as demonstrated by the decision of several NHS Clinical Commissioning Groups in England to add septoplasty to their list of restricted procedures with low clinical value. However, this study shows that septoplasty is not only more effective than non-surgical management for nasal obstruction in adults with a deviated septum, but also potentially cost-effective, depending on the selected perspective, cost-effectiveness threshold, and time horizon. From a healthcare perspective, septoplasty is already cost-effective after 24 months against the Dutch threshold of $€ 20,000$ per QALY and the British threshold of $£ 20,000(€ 22,814)$ per QALY. From a societal perspective, septoplasty's incremental costs per QALY gained are expected to fall below the Dutch costeffectiveness threshold over the course of the third or fourth postoperative years. With this study, we aim to inspire a debate between all stakeholders (including patients, healthcare providers, health insurance companies, and policy-makers) as the first step towards evidencebased policy development on septal surgery in this target population, taking the above findings into account. One of the issues that needs to be addressed is the indication for septoplasty. In light of our findings, existing restrictions placed on the use and reimbursement of septoplasty may seem inopportune. At the same time, we must remain cautious of extending the indication beyond the current evidence base.

\section{Conclusions}

Septoplasty is both more effective and more costly than non-surgical management for nasal obstruction in adults with a deviated septum. Depending on the selected perspective, cost-effectiveness threshold, and time horizon, septoplasty has the potential to be cost-effective. Despite considerable uncertainty, septoplasty seems cost-effective from a healthcare perspective, after 24 months against a threshold of $€ 20,000$ per QALY. From a societal perspective, septoplasty is not yet cost-effective after 24 months, but it comes closer to the cost-effectiveness threshold as time passes by.

\section{Supplementary information}

Supplementary information accompanies this paper at https://doi.org/10. 1186/s12916-020-01562-5.

Additional file 1. Missing data and single imputation nested in the bootstrap percentile method.

\section{Abbreviations}

EQ-5D-3L: EuroQol five dimensions three levels; ICER: Incremental costeffectiveness ratio; NHS: National Health Service; NICE: British National
Institute for Health and Care Excellence; NIHR: British National Institute for Health Research; NOSE: Nasal obstruction symptom evaluation; PNIF: Peak nasal inspiratory flow; PSS: Personal social services; QALY: Quality-adjusted life year; RCT: Randomized controlled trial

\section{Acknowledgements}

We thank the patients who participated in the trial; the ear, nose, and throat surgeons who contributed to the enrollment of trial participants; the independent data managers for creating the trial randomization website and overseeing the data collection; Carine Hendriks for the support in coordinating the study; Tim Govers for the data monitoring; medical students Charlotte Michels, Sanne Leuwerink, Beau de Korte, and Steef van den Broek for the administrative and practical support; Eddy Adang for his advice regarding the study design; and the Dutch Ear, Nose, and Throat Society for supporting the trial's initiation and conduct.

\section{Authors' contributions}

$\mathrm{NvH}$ and MR conceived the study and initiated the study design. MvE, $\mathrm{NvH}_{\text {, }}$ and MR conducted the study. All authors performed the data analysis. All authors had full access to all of the data and can take responsibility for the integrity of the data and the accuracy of the data analysis. All authors drafted this manuscript and approved the final version. NvH and MR are the principal investigators. The corresponding author (MvE) attests that all listed authors meet the authorship criteria and that no others meeting the criteria have been omitted. The authors read and approved the final manuscript.

\section{Funding}

The study was funded by ZonMw (the Netherlands Organization for Health Research and Development), project number 837002001 . The funder had no role in the study design; in the collection, analysis, and interpretation of the data; in the writing of the report; and in the decision to submit the article for publication. All authors were independent of the funder. All authors had full access to all of the data and can take responsibility for the integrity of the data and the accuracy of the data analysis. There was no commercial involvement in the study.

\section{Availability of data and materials}

De-identified participant data will be made available on reasonable request to researchers whose proposed use of the data has been approved by the principal investigators ( $\mathrm{NvH}$ and $\mathrm{MR}$ ), with a signed data access agreement and only for purposes specified in the approved research proposal. Requests for data must be sent to Niels.vanHeerbeek@radboudumc.nl. The study protocol is publicly available online.

\section{Ethics approval and consent to participate}

The study was approved by the accredited medical ethics committee (Commission for Research in Human Subjects, in Dutch: Commissie Mensgebonden Onderzoek, region Arnhem-Nijmegen) of Radboud University Medical Center, Nijmegen, registration number 2013/147. The study was monitored in accordance with Good Clinical Practice. Informed consent was obtained from all participants.

Consent for publication

Not applicable.

\section{Competing interests}

The authors declare that they have no competing interests.

\section{Author details}

${ }^{1}$ Department of Otorhinolaryngology, Radboud Institute for Health Sciences, Radboud University Medical Center, Route 377, P.O. Box 9101, 6500 HB Nijmegen, the Netherlands. '2Department of Operating Rooms, Radboud Institute for Health Sciences, Radboud University Medical Center, Route 715, P.O. Box 9101, 6500 HB Nijmegen, the Netherlands. ${ }^{3}$ Department of Health Evidence, Radboud Institute for Health Sciences, Radboud University Medical Center, Route 133, P.O. Box 9101, 6500 HB Nijmegen, the Netherlands. 
Received: 26 July 2019 Accepted: 17 March 2020

Published online: 01 May 2020

\section{References}

1. Manoukian PD, Wyatt JR, Leopold DA, Bass EB. Recent trends in utilization of procedures in otolaryngology-head and neck surgery. Laryngoscope. 1997;107:472-7.

2. NHS National Institute for Health Research, Health Technology Assessment Programme. Septoplasty for a deviated nasal septum. 2015. https://njladmin.nihr.ac.uk/document/download/2012713 (Accessed 17 July 2019).

3. ENT UK. Nasal septal surgery: ENT UK position paper. 2010. http://www. midlandsnoseclinic.co.uk/app/download/5794535085/ENT+UK+Position+ Paper+on+Septal+Surgery.pdf (Accessed 28 Mar 2019).

4. Dutch ENT Society. The ENT science agenda [Dutch]. 2013. https://www. kno-leden.nl/leden/public/doc/KNO\%20wetenschapsagenda\%20definitief. pdf (Accessed 18 Aug 2015).

5. Van Egmond MM, Rovers MM, Tillema AH, Van Heerbeek N. Septoplasty for nasal obstruction due to a deviated nasal septum in adults: a systematic review. Rhinology. 2018;56:195-208.

6. NHS Wolverhampton Clinical Commissioning Group. Procedures of Low Clinical Value (PoLCV) commissioning policy. 2015. https:// wolverhamptonccg.nhs.uk/about-us/the-governing-body/board-papers/2 015-1/march-1/1156-i-agenda-item-1 1 b-harmonised-polcv-policy-v4-10march-2015-1/file (Accessed 21 June 2019).

7. NHS Stafford and Surrounds Clinical Commissioning Group. Excluded and restricted procedures policy. 2017. http://www.staffordsurroundsccg.nhs.uk/ about-us/our-policies/clinical/506-excluded-and-restrict-procedures-policy-2 017/file (Accessed 21 June 2019).

8. Beule AG, Riedel F, Deitmer T, Dazert S. Wissenschaftlich begründete Indikation zur Nasen-Septumplastik]. 2019. https://cdn.hno.org/media/PDF/stellungnahmedghno-khc-nasen-septumplastik-3-19.pdf (Accessed 21 June 2019).

9. Van Egmond MM, Rovers MM, Hannink G, Hendriks CT, Van Heerbeek N. Septoplasty with or without concurrent turbinate surgery versus nonsurgical management for nasal obstruction in adults with a deviated septum: a pragmatic, randomised controlled trial. Lancet. 2019;394:314-21.

10. Van Egmond MM, Rongen JJ, Hedeman CJ, van Heerbeek N, Rovers MM. Septoplasty versus non-surgical management for nasal obstruction due to a deviated nasal septum in adults: a modelling study of cost-effectiveness. Clin Otolaryngol. 2018;44:53-62.

11. Neumann PJ, Thorat T, Shi J, Saret CJ, Cohen JT. The changing face of the cost-utility literature, 1990-2012. Value Health. 2015;18:271-7.

12. Schulz KF, Altman DG, Moher D. CONSORT 2010 statement: updated guidelines for reporting parallel group randomised trials. BMJ. 2010;340:c332.

13. Husereau D, Drummond M, Petrou S, et al. Consolidated Health Economic Evaluation Reporting Standards (CHEERS) statement. BMJ. 2013;346:f1049.

14. Van Egmond MM, Rovers MM, Hendriks $C T$, van Heerbeek N. Effectiveness of septoplasty versus non-surgical management for nasal obstruction due to a deviated nasal septum in adults: study protocol for a randomized controlled trial. Trials. 2015;16:500.

15. Taves DR. Minimization: a new method of assigning patients to treatment and control groups. Clin Pharmacol Ther. 1974;15:443-53.

16. Pocock SJ, Simon R. Sequential treatment assignment with balancing for prognostic factors in the controlled clinical trial. Biometrics. 1975;31:103-15.

17. Akoglu E, Karazincir S, Balci A, Okuyucu S, Sumbas H, Dagli AS. Evaluation of the turbinate hypertrophy by computed tomography in patients with deviated nasal septum. Otolaryng Head Neck. 2007;136:380-4.

18. Jonsson B. Ten arguments for a societal perspective in the economic evaluation of medical innovations. Eur J Health Econ. 2009:10:357-9.

19. National Institute for Health and Care Excellence. NICE guide to the methods of technology appraisal. 2013. https://www.nice.org.uk/process/ pmg9/resources/guide-to-the-methods-of-technology-appraisal-2013-pdf-2 007975843781 (Accessed June 21 2019).

20. Brouwer WB, Van Exel NJ, Baltussen RM, Rutten FF. A dollar is a dollar is a dollar - or is it? Value Health. 2006;9:341-7.

21. Zorginstituut Nederland. Guideline for economic evaluations in healthcare. 2016. https://english.zorginstituutnederland.nl/binaries/zinleng/documents/reports/2016/06/16/guideline-for-economic-evaluationsin-healthcare/Guideline+for+economic+evaluations+in+healthcare.pdf (Accessed 24 June 2019).
22. EuroQol Group. EQ-5D-3L user guide: basic information on how to use the EQ-5D-3L instrument. 2018. https://eurogol.org/wp-content/uploads/201 8/12/EQ-5D-3L-User-Guide_version-6.0.pdf (Accessed 21 June 2019).

23. Lamers LM, McDonnell J, Stalmeier PF, Krabbe PF, Busschbach JJ. The Dutch tariff: results and arguments for an effective design for national EQ-5D valuation studies. Health Econ. 2006;15:1121-32.

24. Stewart MG, Witsell DL, Smith TL, Weaver EM, Yueh B, Hannley MT. Development and validation of the Nasal Obstruction Symptom Evaluation (NOSE) scale. Otolaryng Head Neck. 2004;130:157-63.

25. Van Zijl F, Timman R, Datema FR. Adaptation and validation of the Dutch version of the nasal obstruction symptom evaluation (NOSE) scale. Eur Arch Otorhinolaryngol. 2017;274:2469-76.

26. Ziai H, Bonaparte JP. Determining a successful nasal airway surgery: calculation of the patient-centered minimum important difference. Otolaryng Head Neck. 2017:157:325-30.

27. Van Egmond MM, van Heerbeek N, Ter Haar EL, Rovers MM. Clinimetric properties of the Glasgow Health Status Inventory, Glasgow Benefit Inventory, Peak Nasal Inspiratory Flow, and 4-Phase Rhinomanometry in adults with nasal obstruction. Rhinology. 2017;55:126-34.

28. Zorginstituut Nederland. Pharmacotherapeutic compass [Dutch]. 2017. https://www.farmacotherapeutischkompas.nl/ (Accessed 21 June 2019).

29. European Central Bank. Euro foreign exchange reference rates. 2017. https:// www.ecb.europa.eu/stats/policy_and_exchange_rates/euro_reference_ exchange_rates/html/eurofxref-graph-gbp.en.html (Accessed 21 June 2019).

30. Briggs $\mathrm{AH}$, Wonderling $\mathrm{DE}$, Mooney $\mathrm{CZ}$. Pulling cost-effectiveness analysis up by its bootstraps: a non-parametric approach to confidence interval estimation. Health Econ. 1997;6:327-40.

31. Van Hout BA, Al MJ, Gordon GS, Rutten FF. Costs, effects and C/E-ratios alongside a clinical trial. Health Econ. 1994;3:309-19.

32. Brand J, Van Buuren S, Le Cessie S, Van den Hout W. Combining multiple imputation and bootstrap in the analysis of cost-effectiveness trial data. Stat Med. 2019;38(2):210-20.

33. Herdman M, Gudex C, Lloyd A, et al. Development and preliminary testing of the new five-level version of EQ-5D (EQ-5D-5L). Qual Life Res. 2011;20: $1727-36$.

\section{Publisher's Note}

Springer Nature remains neutral with regard to jurisdictional claims in published maps and institutional affiliations.
Ready to submit your research? Choose BMC and benefit from:

- fast, convenient online submission

- thorough peer review by experienced researchers in your field

- rapid publication on acceptance

- support for research data, including large and complex data types

- gold Open Access which fosters wider collaboration and increased citations

- maximum visibility for your research: over $100 \mathrm{M}$ website views per year

At $\mathrm{BMC}$, research is always in progress.

Learn more biomedcentral.com/submissions 